\title{
Spatial and Temporal Variation of LURR and its Implication for the Tendency of Earthquake Occurrence in Southern California
}

\author{
YongXian Zhang ${ }^{1}$, Xiang-Chu Yin ${ }^{1,2}$, and Keyin PenG ${ }^{1,2}$
}

\begin{abstract}
Based on the theory of LURR and its recent development, spatial and temporal variation of $Y / Y_{c}$ (value of LURR/critical value of LURR) in the Southern California region during the period from 1980 through March, 2001 was studied. According to the previous study on the fault system and stress field in Southern California, we zoned the Southern California region into 11 parts in each of which the stress field is almost uniform. With the time window of one year, time moving step of three months, space window of a circle region with a radius of $100 \mathrm{~km}$ and space moving step of 0.25 degree in latitude and longitude direction, the evolution of $Y / Y_{c}$ were snapshot. The scanning results show that obvious $Y / Y_{c}$ anomalies occurred before $5 / 6$ of strong earthquakes considered with a magnitude of 6.5 or greater. The critical regions of $Y / Y_{c}$ are near the epicenters of the strong earthquakes and the $Y / Y_{c}$ anomalies occur months to years prior to the earthquakes. The tendency of earthquake occurrence in the California region is briefly discussed on the basis of the examination of $Y / Y_{c}$.
\end{abstract}

Key words: LURR, $Y / Y_{\mathrm{c}}$, stress field, spatial and temporal scanning, Southern California region, tendency of earthquake occurrence.

\section{Introduction}

The Load-Unload Response Ratio (LURR) method, put forward by YIN (1987), has been tested in many regions in China and some regions in the United States, Japan and Australia. The method has shown considerable promise for intermediateterm earthquake prediction (YIN and YIN, 1991; YIN et al., 1995, 2000, 2001).

The physical essence of an earthquake is failure or instability of the focal media. When a seismogenic system is in a stable state, its response to loading is similar to its response to unloading, whereas when the system is in an unstable state, the responses to loading and unloading become quite different (YIN, 1987; YIN and YIN, 1991; YIN, et al., 1995, 2000). LURR (Load/ Unload Response Ratio) is defined as

$$
Y=X^{+} / X^{-}
$$

${ }^{1}$ The Center for Analysis and Prediction, China Earthquake Administration, Beijing 100036, China. E-mail: zhang.yongxian@263.net, E-mail: yinxc@btamail.net.cn, E-mail: peng_keyin@163.com

${ }^{2}$ LNM, Institute of Mechanics, Chinese Academy of Sciences, Beijing 100080, China.

E-mail: yin@lnm.imech.ac.cn 
where $X^{+}$and $X^{-}$are the response rates during loading and unloading measured by some method. According to the LURR idea, when a seismogenic system is in a stable or linear state $Y \sim 1$ whereas when the system lies outside of the linear state $Y>1$. In earthquake prediction practice with LURR, loading and unloading periods are determined by calculating perturbations in the Coulomb failure stress induced by earth tides. Experimental and numerical simulation have validated LURR (MORA et al., 2000, 1999; WANG et al. 1999, 2000, 1999). In retrospective studies, high $Y$ values have been observed months to years prior to most significant events and some successful intermediate-term earthquake predictions have been made (YIN et al., 2000).

In this paper we report the results of our study on LURR variation in the Southern California region from 1980 to March, 2002 using a spatial and temporal scanning method. Frameworks of the fault system and stress field for Southern California were obtained from the SCEC (Southern California Earthquake Center) Data Center via INTERNET (http://www.data.scec.org), and the earthquake catalogue was taken from the CNSS (Council of the National Seismic System, now ANSS - Advanced National Seismic System) via INTERNET (http://www.anss.org).

\section{Method to Calculate LURR}

\subsection{Calculation of LURR}

In the LURR theory, $Y$ is defined directly by means of seismic energy as follows:

$$
Y_{m}=\frac{\left[\sum_{i=1}^{N^{+}} E_{i}^{m}\right]_{+}}{\left[\sum_{i=1}^{N^{-}} E_{i}^{m}\right]_{-}}
$$

where $E$ denotes seismic energy which can be calculated according to the GutenbergRichter formula (KANAMORI and ANDERSON, 1975; Bullen and BOLT, 1985), the "+" sign means loading and "-" means unloading, $m=0$ or $1 / 3$ or $1 / 2$ or $2 / 3$ or 1 . When $m=1, E^{\mathrm{m}}$ is exactly the energy itself; for $m=1 / 2, E^{\mathrm{m}}$ denotes the Benioff strain; for $m=1 / 3,2 / 3, E^{\mathrm{m}}$ represents the linear scale and area scale of the focal zone, respectively; for $m=0, Y$ is equal to $N^{+} / N^{-}$, and $N^{+}$and $N^{-}$denote the number of earthquakes which occur during the loading and unloading periods.

In this paper, $m$ is chosen as $1 / 2$, which means that $Y$ is determined by the ratio of Benioff strain during the loading period over the unloading period.

Since the preparation and occurrence process of earthquakes are controlled not only by deterministic dynamical law but also affected by stochastic or disorder factors, ZHUANG and YIN (1999) studied the influence of random factors on LURR in order to estimate the threshold $Y$ value, which can be regarded as an earthquake precursor within a specified confidence level. They gave the critical value of LURR 
$Y_{\mathrm{c}}$ that depends on the number of earthquakes under different specified confidence levels. For instance, at the confidence level of $90 \%, Y_{\mathrm{c}}$ is equal to 3.18 if the number of earthquakes in the time and space window is 20, which means that $Y$ should be equal to or greater than 3.18 for the medium to be considered in an unstable state when the number of earthquakes is 20 . For the confidence level of $99 \%, Y_{\mathrm{c}}$ is 7.69 if the number of earthquakes in the specific time and space window is 20 . The greater the earthquake number is, the lower the $Y_{\mathrm{c}}$ (critical value of LURR).

In this paper we give critical space-time regions of LURR by $Y / Y_{\mathrm{c}}$ instead of $Y$ under a confidence level of $99 \%$.

\subsection{Determination of Loading and Unloading}

Loading and unloading periods are determined by calculating perturbations in the Coulomb Failure Stress (CFS) (e.g., Harris, 1998; Reasenberg and Simpson, 1992) induced by earth tides.

$$
C F S=\tau_{n}+f \sigma_{n},
$$

where $\sigma_{n}$ stands for normal stress, $\tau_{n}$ denotes shear stress, $f$ represents the coefficient of internal friction, and $\boldsymbol{n}$ is the normal direction of the fault plane on which CFS reaches its maximum. When the increment of Coulomb Failure Stress $(\triangle C F S)$ is positive, it is in a loading state; otherwise, when $\triangle C F S$ is negative, it is in an unloading state.

Stress in the crust $\sigma_{i j}$ consists of tectonic stress $\sigma_{i j}^{T}$ and the stress induced by the earth $\sigma_{i j}^{t}$ since the level of $\sigma_{i j}^{T}$ (on the order of $10^{6}-10^{8} \mathrm{~Pa}$ ) far exceeds the level of $\sigma_{i j}^{t}$ $\left(10^{3}-10^{4} \mathrm{~Pa}\right)$, directions of the principle stress in the crust and the direction of $n$ can be determined from the tectonic stress only. However, the rate of change of the tidal stress is considerably larger than that of the tectonic stress (VIDALI, et al., 1998), thus $\triangle C F S$ is mainly due to stress induced by tide, which can be calculated precisely.

\subsection{Tectonic Stress Field in Southern California}

An outline of the stress field in Southern California can be obtained from the world stress map (ZовACK, 1992). The stress field is supplemented by the fault system in Southern California which is provided by SCEC (Southern California Data Center). With these two sets of information, we divided the Southern California region into 11 parts, in each of which the stress field is almost uniform. The divisions of Southern California based on the stress field are shown in Figure 1.

\section{Data and Scanning Parameters}

The earthquake catalogue we use in this paper is from CNSS (Council of the National Seismic System). 


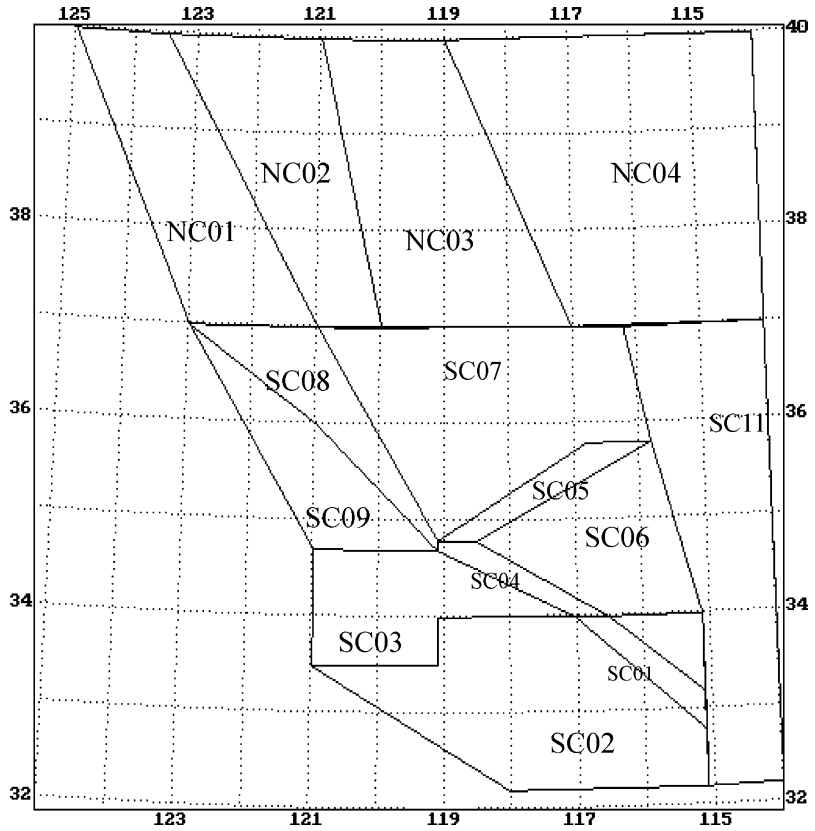

Figure 1

Divisions of Southern California based on the stress field.

In order to speed up the calculations and avoid disturbance from outstanding earthquakes, we chose magnitude thresholds according to the Gutenberg-Richter relation in each unit area.

The scanning parameters are as follows:

Time window: 1 year

Time moving step: 3 months

Space window: $\mathrm{R}=100 \mathrm{~km}$

Space moving step: $0.25^{\circ}$ in latitude and longitude direction.

That is, a circle region with a radius of $100 \mathrm{~km}$ was selected as the spatial window within which a value of $Y / Y_{\mathrm{c}}$ (LURR/critical LURR) was calculated for a specific time window (1 year), then the circle center was moved step by step in both latitude and longitude by increments of 0.25 degrees.

\section{4. $Y / Y_{c}$ Anomalies before Strong Earthquakes and Tendency of Earthquake Occurrence in Southern California}

Eighty-six images of $Y / Y_{\mathrm{c}}$ contours during the period from 1980 to March, 2002 were obtained based on the scanning parameters listed above. The main results were listed below. 


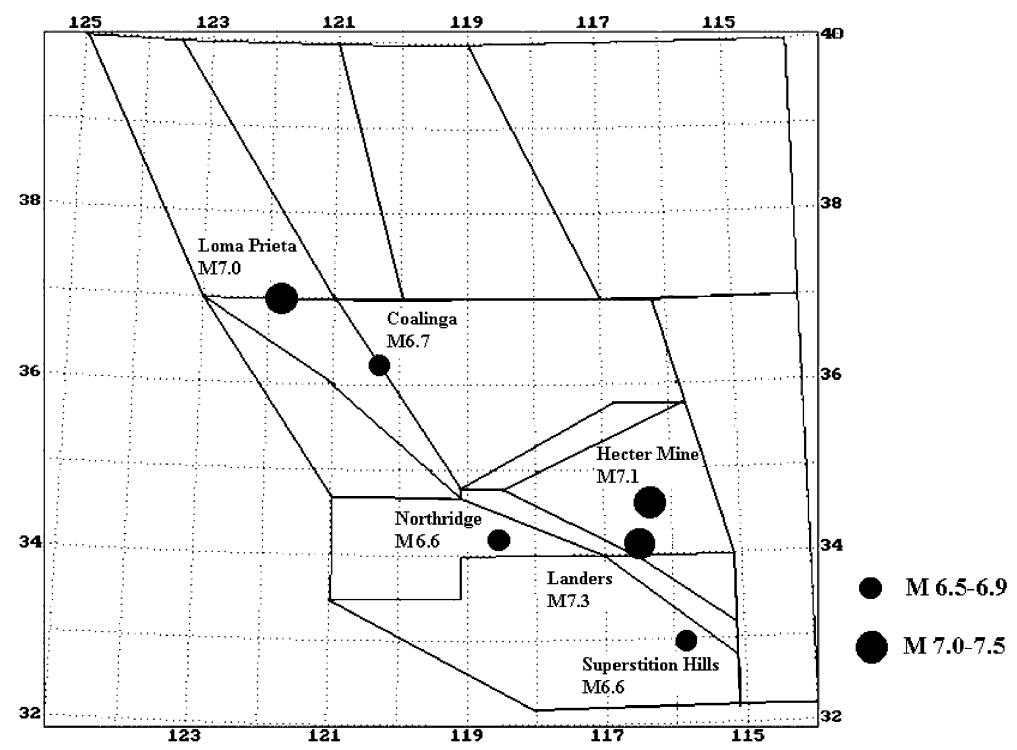

Figure 2

Six strong earthquakes $(M \geq 6.5)$ in Southern California during the period from 1980 through 2001.

\section{$4.1 Y / Y_{c}$ before Six Strong Earthquakes in Southern California}

Six strong earthquakes $(M \geq 6.5)$ occurred in Southern California during the period from 1980 through 2001, as shown in Figure 2. These earthquakes are listed in Table 1.

Our results indicate that obvious $Y / Y_{\mathrm{c}}$ anomalies occurred 1-2 years before five of the six strong earthquakes $(M \geq 6.5)$ in Southern California during the period from 1980 through 2001, as shown in Table 1.

The above results show that strong earthquakes occurred near regions of anomalous $Y / Y_{c}$. Anomalous $Y / Y_{c}$ was discovered about 1-2 years before an

Table 1

$Y / Y_{c}$ anomalies before six strong earthquakes in Southern California during the period from 1980 through 2001.

\begin{tabular}{ccccc}
\hline Date & Epicenter & $\begin{array}{c}\text { Magnitude/ } \\
\Delta(\mathrm{Km})\end{array}$ & $\begin{array}{c}\text { Max. } \\
Y / Y_{c}\end{array}$ & $\begin{array}{c}\text { Lasting time of } \\
\text { anomalous } Y / Y_{c} \\
\text { (month) }\end{array}$ \\
\hline 1983.5 .2 & $\left(36.23^{\circ} \mathrm{N}, 120.32^{\circ} \mathrm{W}\right)$ Coalinga & $6.7 / ?$ & $?$ & $?$ \\
1987.11 .24 & $\left(33.01^{\circ} \mathrm{N}, 115.85^{\circ} \mathrm{W}\right)$ Superstition Hills & $6.6 / 0$ & 1.4 & 21 \\
1989.10 .18 & $\left(37.04^{\circ} \mathrm{N}, 121.88^{\circ} \mathrm{W}\right)$ Loma Prieta & $7.0 / 100$ & 1.2 & 24 \\
1992.6 .28 & $\left(34.20^{\circ} \mathrm{N}, 116.44^{\circ} \mathrm{W}\right)$ Landers & $7.3 / 100$ & 1.0 & 18 \\
1994.1 .17 & $\left(34.21^{\circ} \mathrm{N}, 118.54^{\circ} \mathrm{W}\right)$ Northridge & $6.6 / 80$ & 1.0 & 25 \\
1999.10 .16 & $\left(34.59^{\circ} \mathrm{N}, 116.27^{\circ} \mathrm{W}\right)$ Hector Mine & $7.1 / 100$ & 1.4 & 15 \\
\hline
\end{tabular}

Note: $\Delta(\mathrm{km})$ is the distance between earthquake epicenter and the maximum $Y / Y_{c}$ point. 

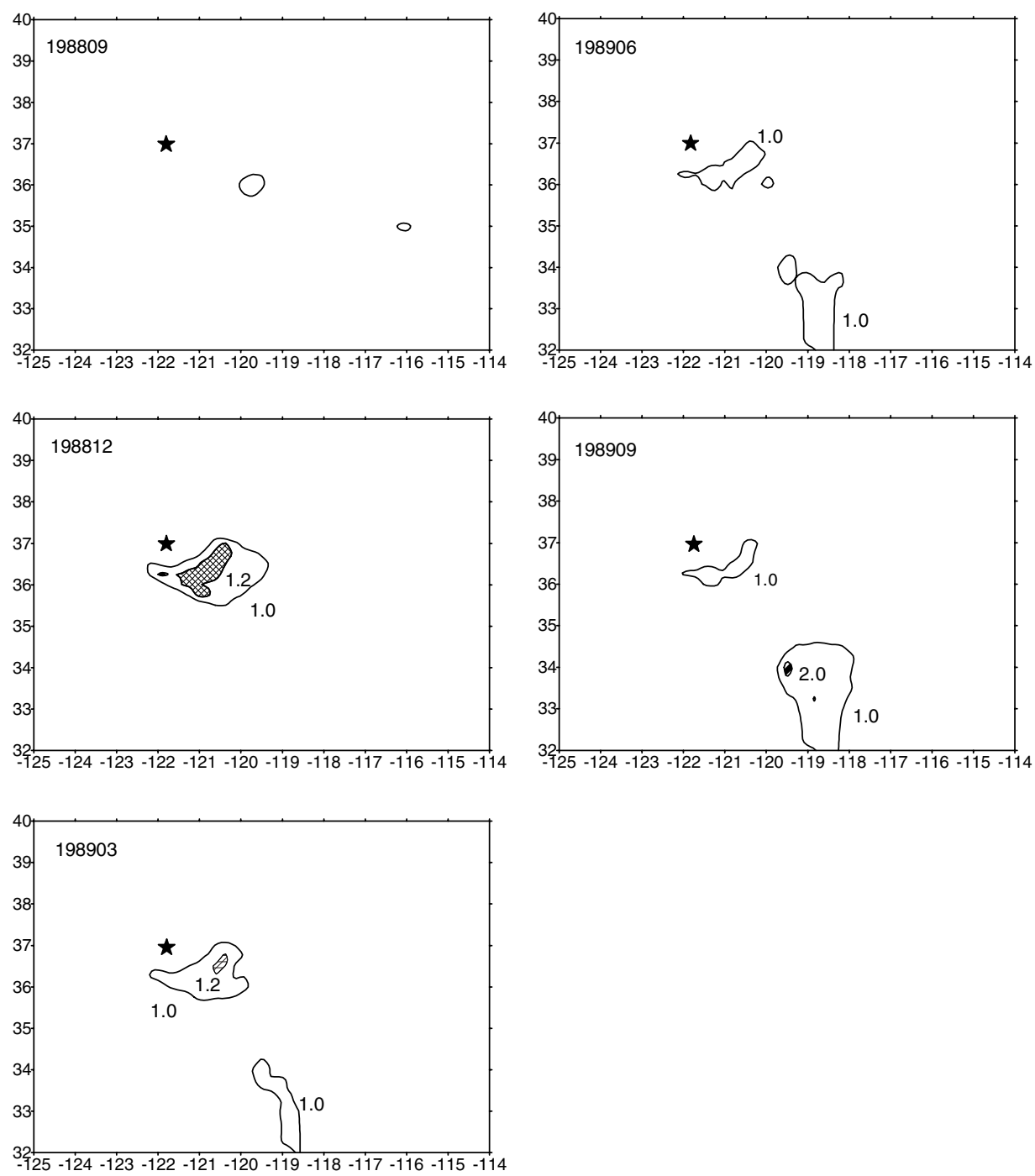

Figure 3

$Y / Y_{c}$ contour from Sep. 1988 to Sep. 1989 before the Loma Prieta Earthquake. A mark of pentagon stands for the epicenter of the Loma Prieta earthquake; numeral in the upper left corner represents the time (year and month).

upcoming earthquake. For example, before the 1989 Loma Prieta M7.0 earthquake, the anomalous $Y / Y_{c}$ region appeared from 1988. Figure 3 shows the evolution of $Y / Y_{c}$ contours from Dec. 1988 to Sep. 1989. The Loma Prieta earthquake occurred at a location about $100 \mathrm{~km}$ to the northwest of the anomalous $Y / Y_{\mathrm{c}}$ region. We also see another anomalous region of $Y / Y_{\mathrm{c}}$ from Mar. 1989 to Sep. 1989 in Figure 3, which covered the region of $32-34.6^{\circ} \mathrm{N}, 117.7-119.7^{\circ} \mathrm{E}$. This anomalous region might be 


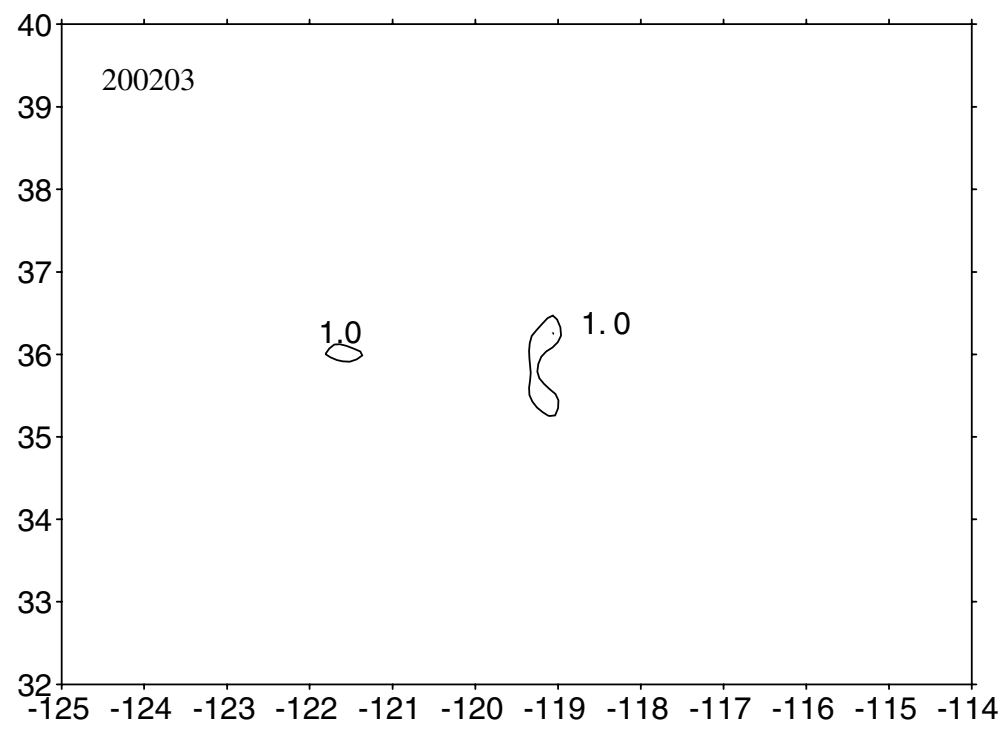

Figure 4

$Y / Y_{\mathrm{c}}$ contour in March 2002.

related to the $M 5.4$ earthquake $\left(34.14^{\circ} \mathrm{N}, 117.70^{\circ} \mathrm{E}\right)$ on Feb. 28,1990 and the $M 5.8$ earthquake $\left(34.27^{\circ} \mathrm{N}, 117.99^{\circ} \mathrm{E}\right)$ on June 28,1991 , which were the only two midstrong earthquakes in this region during the period from 1990 to 1991.

\section{$4.2 Y / Y_{c}$ in periods and regions without strong earthquakes $(M \geq 6.5)$ in Southern California}

Few anomalous $Y / Y_{\mathrm{c}}$ regions occurred during the investigated periods without strong earthquakes $(M \geq 6.5)$. For example, no earthquakes greater than $M 6.5$ occurred after the Hector Mine M7.1 earthquake, and there was no obvious $Y / Y_{\mathrm{c}}$ anomaly during the period from 2000 through 2001. A few anomalous $Y / Y_{\mathrm{c}}$ regions appeared without succeeding strong earthquakes, which might indicate that the earthquake preparation process is very complex.

\subsection{Tendency of Earthquake Occurrence in Southern California}

Our results show that there were no obvious $Y / Y_{\mathrm{c}}$ anomalies from 2000 to 2001, which implies that hazardous earthquakes are not likely to occur in Southern California in the near future. Two small anomalous $Y / Y_{\mathrm{c}}$ regions in Southern California in March 2002 (Fig. 4) may indicate an occurrence of a moderate earthquake of about magnitude 5 around $\left(36^{\circ} \mathrm{N}, 119^{\circ} \mathrm{W}\right)$ and $\left(36^{\circ} \mathrm{N}, 121.6^{\circ} \mathrm{W}\right)$ within about 1 year. If the $Y / Y_{c}$ anomalous region grows larger and lasts for half to one year or more, there might be a stronger earthquake in these regions. 


\section{Conclusions and Discussion}

In this paper, the variation of $Y / Y_{c}$ in Southern California during the period from 1980 through March, 2002 was studied by a spatial and temporal scanning method based on the stress field in Southern California. The calculating results covering 22 years within which 6 strong earthquakes with M6.5 or greater occurred in Southern California. According to the results above, the following conclusions could be drawn:

1. Obvious $Y / Y_{c}$ (value of LURR/critical value of LURR) anomalies occurred near the epicenters of upcoming 5 strong earthquakes out of 6 with $M 6.5$ or greater during the period from 1980 through 2001 in Southern California. The amplitude of $Y / Y_{c}$ is within 1.0 to 1.4 and the nearest distance from the epicenter to the $Y / Y_{c}$ anomalous region is from $0 \mathrm{~km}$ to $100 \mathrm{~km}$.

2. The size of the anomalous region of $Y / Y_{c}$ is $100-300 \mathrm{~km}$, which might imply the scale of the seismogenic region of the upcoming strong earthquake.

3. The anomaly of $Y / Y_{c}$ began about 1 to 2 years prior to the upcoming strong earthquake and underwent a process of development firstly and weakening subsequently. Most of the strong earthquakes occurred in the weakening stage of $Y / Y_{c}$.

4. According to the above results, LURR is a promising approach to intermediateterm earthquake prediction before strong earthquakes with $M 6.5$ or greater in Southern California.

In comparison with the previous study of LURR in China Mainland (e.g., YIN et al., 1995), the lasting time of LURR anomaly in Southern California is shorter than that in China, which might reflect the difference of earthquake cycle between Southern California and China Mainland under different tectonic fields.

The above results depend on the details of stress field, earthquake catalogue and scanning parameters, consequently we might heighten the credibility of LURR and improve the accuracy of earthquake prediction if detailed knowledge of the stress field in Southern California and a higher quality of earthquake catalogues could be accessed. Meanwhile, suitable scanning parameter might improve the results.

\section{Acknowledgements}

Funding support is gratefully acknowledged by NSFC under grant No. 10232050. Special Funds for Major State Basic Research Project under grant No. 2002 CB412706 and Supercomputing Center of Computer Network Information Center, Chinese Academy of Science (INF105-SCE-2-02). We also express our thanks to QUAKES and CNSS. The reviews of Akio Yoshida and an unknown reviewer assisted our improvment of the manuscript. 


\section{REFERENCES}

Bullen, K. E., and Bolt, B. B. (1985), An Introduction to the Theory of Seismology (Cambridge University Press, Cambridge Press 1985).

HARris, R. A. (1998), Introduction to Special Section: Stress Triggers, Stress Shadows, and Implication for Seismic Hazard, J. Goephys. Res. 103, 24,347-24,358.

Kanamori, H., and Anderson, D. L. (1975), Theoretical Basis of Some Empirical Relation in Seismology, Bull. Seismol. Soc. Am. 65, 1073-1096.

Mora, P., Place, D., Wang, Y., Yin, X., Peng, K., and Weatherley, D. (2000), Earthquake Forecasting: Retrospective Studies in Australia - the Newcastle and Burra Earthquakes and Numerical Simulation of the Physical Process, AEES (Australian Earthquake Engineering Society) Annual Meeting, November' 2000, Hobart, Australia.

Mora, P., Place, D., Wang, Y., Yin, X. (2000), Simulation of Load-Unload Response Ratio in the Lattice Solid Model, AGU (American Geophysical Union) 2000 Fall Meeting, San Francisco, 10-17, December 2000.

Resenberg, P. A., and Simpson, R. W. (1992), Response of Regional Seismicity to the Static Stress Change Produced by the Loma Prieta Earthquake, Science 255, 1687-1690.

Vidali, J. E., Agnew, D. C., Johnston, M. J. S. and Oppenheimer, D. H. (1998), Absence of Earthquake Correlation with Earth Tides: An Indication of High Preseismic Fault Stress Rate, J. Geophys. Res. 103, 24,567-24,572.

WANG, Y., YIN X.-C., and WAng, H., (1999), The Simulation of Rock Experiment on Load/Unload Response Ratio on Earthquake Prediction, Earthquake Research in China, 14, 126-130.

Yin, X. C., Mora, P., Peng, K., Wang, Y., and Weatherly, D. (2001), Load-unload Response Ratio and Accelerating Moment/Energy Release, Critical Region Scaling and Earthquake Prediction, The $2^{\text {nd }}$ ACES Workshop, October 15-20, 2000, Tokyo and Hakone, Japan, Workshop Abstract, pp 362-368.

YIN X. C., and YIN, C. (1991), The Precursor of Instability for Nonlinear Systems and its Application to Earthquake Prediction, Science in China 34, 977-986.

YIN, X. C. (1987), A New Approach to Earthquake Prediction, Earthquake Research in China 3, 1-7 (in Chinese with English abstract).

Yin, X. C., Chen, X. Z., Song, Z. P., and Yin, C. (1995), A new Approach to Earthquake Prediction: the Load/Unload Response Ratio (LURR) Theory, Pure Appl. Geophys. 145, 701-715.

Yin, X. C., Wang, Y. C., Peng, K. Y., and Bai, Y. L. (2000), Development of a New Approach to Earthquake Prediction: Load/Unload Response Ratio (LURR) Theory, Pure Appl. Geophys. 157, 23652383.

Wang, Y. C., Yin, X. C., Peng, K. -Y. (1999), Numerical Simulation on Load/Unload Response Ratio Theory, Chinese Journal of Geophysics 42, (4), 527-536.

Wang Y., Yin, X. C., Ke, F. J., XIA, M.- F., and Peng, K. (2000), Numerical Simulation of Rock Failure and Earthquake Process on Mesoscopic Scale, Pure Appl. Geophys. 157, 1905-1928.

Zhuang, J. C., and YIN X. C. (1999), Random Distribution of the Load/Unload Response Ration (LURR) under Assumptions of Poisson Model, Earthquake Research in China 15, 128-138.

Zoвack, M. L. (1992), First- and Second-order Patterns of Stress in the Lithosphere: The World Stress Map Project, J. Geophys. Res. 97, 11,703-11,728.

(Received September 27, 2002, revised April 25, 2003, accepted May 5, 2003)

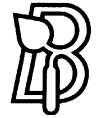

To access this journal online: http://www.birkhauser.ch 